\title{
Relationship between gastric intestinal metaplasia and colorectal neoplasms.
}

\author{
Remzi BESTAS ${ }^{1}$ and Nazım Ekin ${ }^{2}$ \\ ${ }^{1}$ Dicle memorial hospital \\ ${ }^{2}$ Health Sciences University Diyarbakır Gazi Yaşargil Training and Research Hospital
}

April 16, 2021

\begin{abstract}
Background and aims : Colorectal cancers are one of the most common types of cancer. Gastric intestinal metaplasia is considered a precancerous lesion that can progress into gastric cancer. Even though there are previous publications stating that Helicobacter pylori and intestinal metaplasia are related to colorectal adenomas, there are also studies stating the opposite. This study aims to determine the relationship between gastric intestinal metaplasia and colorectal neoplasia. Methods: A total of 214 patients between the ages of 19 and 92 who underwent combined gastroscopy and colonoscopy between August 2016 and April 2020 were included in this retrospective study. Medical records including demographic data, gastroscopy and colonoscopy findings and histopathology results of the patients were reviewed and analyzed. The association of intestinal metaplasia and Helicobacter pylori infection with colorectal neoplasia was evaluated in these patients. Results: The mean age of the patients included in the study was $49.07 \pm 15.80$, and $125(58.4 \%)$ of the patients were male. A statistically significant correlation was found between intestinal metaplasia and colon neoplasm prevalence $(\mathrm{p}=0.03)$. However, such a correlation was not seen between Helicobacter pylori and colon neoplasia. Conclusion: A positive correlation was found between gastric intestinal metaplasia, which is a precancerous lesion, and colon neoplasia. Even though this correlation indicates higher prevalence rates of colon neoplasia in patients with gastric intestinal metaplasia, how to evaluate these patients in terms of colon neoplasia remains a controversial issue.
\end{abstract}

\section{Title page}

Article type: Original article

Title : Relationship between gastric intestinal metaplasia and colorectal neoplasms.

Running title: Intestinal metaplasia and colorectal neoplasm.

Authors: Remzi BEŞTAŞ ${ }^{1}$, Nazım EKİN²

1. Memorial Dicle Hospital, Gastroenterology Department.Diyarbakır, TURKEY. ORCID IDs: https://orcid.org/0000-0001-5852-2117

2. Health Sciences University Diyarbakır Gazi Yaşargil Training and Research Hospital, Gastroenterology Department. Diyarbakır, TURKEY ORCID IDs: https://orcid.org/0000-0001-5302-8953

Author for correspondence: Remzi BEŞTAŞ, MD,

Memorial Dicle Hospital, Gastroenterology Department.

Diyarbakır, TURKEY

Telefon: 05327735176 
Fax: +904123156666

E-mail:bestasr@gmail.com

Financial support and sponsorship: There is no financial support in this study.

Conflicts of interest: There are no conflicts of interest.

\section{ABSTRACT:}

Background and aims : Colorectal cancers are one of the most common types of cancer. Gastric intestinal metaplasia is considered a precancerous lesion that can progress into gastric cancer. Even though there are previous publications stating that Helicobacter pylori and intestinal metaplasia are related to colorectal adenomas, there are also studies stating the opposite. This study aims to determine the relationship between gastric intestinal metaplasia and colorectal neoplasia.

Methods: A total of 214 patients between the ages of 19 and 92 who underwent combined gastroscopy and colonoscopy between August 2016 and April 2020 were included in this retrospective study. Medical records including demographic data, gastroscopy and colonoscopy findings and histopathology results of the patients were reviewed and analyzed. The association of intestinal metaplasia and Helicobacter pylori infection with colorectal neoplasia was evaluated in these patients.

Results: The mean age of the patients included in the study was $49.07 \pm 15.80$, and $125(58.4 \%)$ of the patients were male. A statistically significant correlation was found between intestinal metaplasia and colon neoplasm prevalence $(\mathrm{p}=0.03)$. However, such a correlation was not seen between Helicobacter pylori and colon neoplasia.

Conclusion: A positive correlation was found between gastric intestinal metaplasia, which is a precancerous lesion, and colon neoplasia. Even though this correlation indicates higher prevalence rates of colon neoplasia in patients with gastric intestinal metaplasia, how to evaluate these patients in terms of colon neoplasia remains a controversial issue.

Keywords: Intestinal metaplasia, colorectal neoplasm, Helicobacter pylori

\section{What's already known about this topic?}

The relationship between gastric intestinal metaplasia and colon neoplasia is a controversial issue.

\section{What does this article add?}

Relationship between gastric intestinal metaplasia and colon neoplasm.

Review criteria: how did you gather, select and analyze the information you considered in your review?

Gastric intestinal metaplasia is a risk factor for colon neoplasm.

Message for the clinic: what is the 'take-home' message for the clinician?

Patients with gastric intestinal metaplasia could be encouraged for colonoscopic examination in early stages of life to lower the colorectal neoplasia risk

\section{Introduction}

Gastric cancer, which has a gradually decreasing incidence in many industrialized countries, still remains the second leading cause of cancer related deaths around the world. (1). Gastric cancer is classified into two main types: intestinal and diffuse. Intestinal type gastric cancer is related to premalignant lesions such as chronic atrophic gastritis (AG) and intestinal metaplasia (IM) $(2,3)$. IM, defined as gastric mucosa changing into epithelium with intestinal morphology, is associated with Helicobacter pylori (H. pylori) infection, and during this infection, gastric mucosa progresses into many stages of chronic gastritis, AG and IM $(4,5)$. 
Colorectal cancers (CRC) are one of the most common cancers worldwide. Colorectal carcinogenesis usually originates from colorectal adenomas that develop from normal mucosa and the adenoma - carcinoma sequence $(6,7)$. This process gives us a chance to early diagnose and intervene before the development of cancer. Colorectal adenomas are considered the most important precancerous lesions for CRC. These two diseases, colorectal adenomas and CRC, are collectively referred to as colorectal neoplasia.

Clarifying the pathogenesis and the risk factors of colorectal cancers is of great importance in the early diagnosis and treatment of this cancer (7). Various previous studies were conducted on this matter after H. pylori infection was accepted as a risk factor for colorectal cancer in the 1990s (9). While some studies determined a positive association between $\mathrm{H}$. pylori infection and colorectal cancers (10-15), there were studies stating that this was controversial as well (16-18). In addition, studies investigating the association between gastric IM and colorectal adenomas were also conducted $(7,13,19)$. In a recent study, a significant association between gastric IM and colorectal adenoma prevalence was reported (13). The aim of this study was to evaluate the relationship between $\mathrm{H}$. pylori infection and IM, which is considered a premalignant lesion for gastric cancer, with colon neoplasia.

\section{MATERIAL AND METHODS}

A total of 214 patients, who were indicated for combined gastroscopy and colonoscopy with various prediagnoses between August 2016 and April 2020, were included in this retrospective study. Informed consent forms were obtained from the patients prior to the procedure. Gastroscopic, histopathologic and demographic data of the patients were analyzed and noted down. Patients were separated into two groups according to their endoscopic biopsy results as IM positive and IM negative. Additionally, two groups were created according to the presence of $\mathrm{H}$. pylori infection. The association between gastric intestinal metaplasia and H. pylori infection was evaluated. Patients with colon and gastric surgery histories, patients who were administered eradication therapy for H. pylori, patients who underwent previous polypectomies, patients with inflammatory bowel disease and patients with missing data were excluded from the study. The patients were fully sedated under the supervision of an anesthesiologist and were applied upper and lower endoscopy procedures by a single experienced endoscopist after a minimum of 8 hours of fasting. The absence of abnormal appearance in the examinations was accepted as normal gastroscopic and colonoscopic examination, and biopsies were not taken. Biopsies were taken from patients whose endoscopic examination was suggestive of IM and from suspicious and abnormal lesions. Gastroscopy and colonoscopy procedures were performed with EG-600WR gastroscope and EC-600WL colonoscope (Fujinon, Tokyo, Japan), respectively. This study was approved by the Clinical Research Ethics Committee at Health Sciences University Diyarbakır Gazi Yaşargil Training and Research Hospital.

Statistical analysis: All statistical analyses were performed with the Statistical Package (SPSS) 21.0 software. To evaluate the significance of the difference between the two groups, categorical variables were compared with the Pearson chi-square test or Fisher's exact test, and continuous variables were compared using Student's t-test. Two tailed $\mathrm{p}<0.05$ value was accepted as statistically significant.

\section{RESULTS}

The patients included in the study were between the ages of 19 and 92 , and the mean age was $49.07 \pm 15.80$. Furthermore, $89(41.6 \%)$ of the patients were female and $125(58.4 \%)$ were male. The number of IM positive and IM negative patients were $68(31.8 \%)$ and $146(68.2 \%)$ respectively. A total of $99(46.3 \%)$ patients were positive for $\mathrm{H}$. pylori, and $115(53.7 \%)$ were negative. Patients were separated into two groups according to their H. pylori infection status (Table 1). There was no significant difference between the H. pylori positive and $\mathrm{H}$. pylori negative groups in terms of mean age and gender. No correlation was found between H. pylori infection and colorectal neoplasm prevalence $(\mathrm{p}=0.310)$. Patients in the IM positive group were significantly older than the patients in the IM negative group $(\mathrm{p}=0.000)$, and there were a higher number of male patients in the IM positive group. Colorectal neoplasm prevalence was significantly higher in the IM positive group in comparison with the IM negative group $(\mathrm{p}=0.033)$. The distribution of patients according to IM status was presented in Table 2. All of the patients were separated into four groups (Table 3): Group A: IM positive, 
H. pylori negative; Group B: IM positive, H. pylori negative; Group C: IM negative, H. pylori positive; and Group D: IM negative, H. pylori negative. There was not any significant difference between these four groups in terms of colon neoplasm prevalence.

\section{DISCUSSION}

Colon cancer is one of the leading causes of cancer related mortality and morbidities worldwide. Studies were conducted regarding its etiology exploring the place of a high-fat animal-based diet, consumption of low-fiber foods, smoking (21). There were recent studies focusing on the probability of infectious agents, especially H. pylori, as well. H. pylori infection is considered as the most important risk factor in gastric IM development $(4,21,22)$. Sporadic colorectal cancers mostly originate from adenomatous polyps. With early diagnosis and treatment of colorectal polyps, a significant decrease can be achieved in the incidence and mortality of colorectal cancers $(7,23)$.

The latest research has focused on the role of infectious agents in the prevention of colorectal cancers and the polyp - cancer spectrum $(24,25)$. Although it is not fully understood how H. pylori infection increases the risk of colorectal neoplasia, according to the most commonly described pathogenesis, IM occurs after a long term $\mathrm{H}$. pylori infection, and IM replaces normal gastric cells both in the corpus and the antrum (26). The reduced gastric acid secretion triggered by IM causes hypergastrinemia, which may contribute to colorectal carcinogenesis. In addition, hypochlorhydria affects protein absorption and causes bacterial overgrowth, hence causing an increase in the metabolites and unabsorbed nutrients; and these events may contribute to the formation of colonic diseases and colorectal carcinogenesis $(27,28)$.

The association between H. pylori infection and colorectal neoplasia was first reported in 1997 (9). It was shown in several previous studies that there was a positive correlation between $\mathrm{H}$. pylori infection and colorectal neoplasia (11,29-31). In addition, this correlation was supported in other studies (16,32-34). In their 11-study meta analysis, Zumkeller et al. stated that $\mathrm{H}$. pylori infection caused a minor increase in colorectal cancer risk (35). In our study, it was seen that there was not a significant association between H. pylori infection and gender and age. Contrary to other publications stating that there was a correlation between $\mathrm{H}$. pylori and colorectal neoplasia, in our study, a correlation was not found between $\mathrm{H}$. pylori infection and colon neoplasm risk $(\mathrm{p}=0.310)$. This outcome supports the publications reporting that $\mathrm{H}$. pylori does not increase the colorectal neoplasia risk.

AG and IM prevalence was found to be significantly higher in males in comparison with females (36). There were many studies reporting that 50 years of age and above was an independent risk factor, and IM incidence increased in proportion to age $(37,38)$. Similar to these studies, in our study, IM incidence was found as $41 \%$ in the group aged under 50, and $59 \%$ in the group aged 50 and over. Besides, IM incidence was found to be higher in male patients in comparison with female patients.

In a comprehensive case-control study conducted on 156.000 registered patients, a positive correlation was presented between IM and colorectal adenomas (13). In their 2016 study conducted on 1641 patients aged 40 and over in China, Ye et al. analyzed gastric and colorectal biopsy results and found that Hp infection was significantly associated with a higher risk of colorectal adenoma (39). In addition, an increase in the colorectal adenoma risk was seen in IM positive cases. Moreover, in a more recent study, it was found that individuals with IM had a higher risk of having high-grade intraepithelial neoplasia (40). There are very few studies evaluating the association between $\mathrm{H}$. pylori and IM in our country. In our study, it was found that the IM positive group of patients had a significantly higher risk of colorectal neoplasia in comparison with the IM negative group of patients. There was not any significant difference in terms of colon neoplasia incidence in the analysis of four subgroups including both IM and HP. This result of the group analysis conducted according to the presence of IM supports other publications stating that IM brings a higher risk of colorectal adenoma. Having a limited number of patients in the groups might be the reason why the subgroup analysis gave this result.

In conclusion, even though our study supports the notion that H. pylori infection increases the risk of colorectal neoplasia, this still remains a controversial issue. However, IM, which is considered a chronic 
sequela of $\mathrm{H}$. pylori and a precursor lesion for gastric adenocarcinoma, was found to be a risk factor for colorectal neoplasia, similar to findings of many previous studies. In our study, although H. pylori infection was not found to be a risk factor for colorectal neoplasia, it can be accepted as a potential risk factor for colorectal neoplasia development with IM. Therefore, patients with H. pylori infection and IM could be encouraged for colonoscopic examination in early stages of life to lower the colorectal neoplasia risk. However, it is obvious that there is a need for large-scale studies on this matter.

\section{REFERANS}

1. Katanoda K, Yako-Suketomo H. Comparison of time trends in stomach cancer incidence (1973-2002) in Asia, from cancer incidence in five continents, vols IV-IX. Jpn J Clin Oncol 2009;39:71-72.

2. Ferro A, Peleteiro B, Malvezzi M et al. Worldwide trends in gastric cancer mortality (1980-2011), with predictions to 2015, and incidence by subtype, European Journal of Cancer, 2014;50:1330-44.

3. Park DY, Srivastava A, Kim GH, et al. CDX2 expression in the intestinal-type gastric epithelial neoplasia: frequency and significance, Modern Pathology, 2010;23:54-61

4. Uemura N, Okamoto S, Yamamoto S, et al. Helicobacter pylori infection and the development of gastric cancer. N Engl J Med. 2001;345:784-89.

5. Akiyama J, Uemura N. Intestinal metaplasia subtype and gastric cancer risk, Journal of Gastroenterology and Hepatology. 2009;24:4-6.

6. Fearon ER, Vogelstein B. A genetic model for colorectal tumorigenesis. Cell 1990; 61: 759-67

7. Boyuk B, Ozgur A, Atalay H, et al. Helicobacter pylori infection coexisting with intestinal metaplasia is not associated with colorectal neoplasms Gastroenterology Rev 2019; 14: 133-39

8. Etik DÖ, Turhan N. Perspective of gastroenterologist and pathologist in gastric intestinal metaplasia Güncel gastroenteroloji 2016; 20: 375-82

9. Meucci G, Tatarella M, Vecchi M, et al. High prevalence of Helicobacter pylori infection in patients with colonic adenomas and carcinomas. J Clin Gastroenterol 1997;25: 605-07

10. Fujimori S, Kishida T, Kobayashi T, et al. Helicobacter pylori infection increases the risk of colorectal adenoma and adenocarcinoma, especially in women. J Gastroenterol 2005;40: 887-93

11. Brim H, Zahaf M, Laiyemo AO, et al. Gastric Helicobacter pylori infection associates with an increased risk of colorectal polyps in African Americans. BMC Cancer 2014; 14: 296

12. Inoue I, Mukoubayashi C, Yoshimura N, et al. Elevated risk of colorectal adenoma with Helicobacter pylori-related chronic gastritis: a population-based case-control study. Int J Cancer 2011; 129: 2704-11

13. Sonnenberg A, Genta RM. Helicobacter pylori is a risk factor for colonic neoplasms. Am J Gastroenterol 2013;108: 208-15

14. Hong SN, Lee SM, Kim JH, et al. Helicobacter pylori infection increases the risk of colorectal adenomas: cross-sectional study and meta-analysis. Dig Dis Sci 2012;57: 2184-94

15. Wang F, Sun MY, Shi SL, et al. Helicobacter pylori infection and normal colorectal mucosa-adenomatous polyp-adenocarcinoma sequence: a meta-analysis of 27 case-control studies. Colorectal Dis 2014;16: 246-52

16. Patel S, Lipka S, Shen H, et al. The association of H. pylori and colorectal adenoma: does it exist in the US Hispanic population? J Gastrointest Oncol 2014; 5:463-68

17. Limburg PJ, Stolzenberg-Solomon RZ, Colbert LH, et al. Helicobacter pylori seropositivity and colorectal cancer risk: a prospective study of male smokers. Cancer Epidemiol Biomarkers Prev 2002;11: 1095-99

18. Siddheshwar RK, Muhammad KB, Gray JC, et al. Seroprevalence of Helicobacter pylori in patients with colorectal polyps and colorectal carcinoma. Am J Gastroenterol 2001; 96: 84-88 
19. Qing Y, Wang M, Lin YM, et al. Correlation between Helicobacter pylori-associated gastric diseases and colorectal neoplasia. World J Gastroenterol 2016; 22: 4576-84

20. Gustin DM, Brenner DE. Chemoprevention of colon cancer: current status and future prospects. Cancer Metastasis Rev.2002; 21: 323-48.

21. Meira LB, Bugni JM, Green SL, et al. DNA damage induced by chronic inflammation contributes to colon carcinogenesis in mice. J Clin Invest 2008; 118: 2516-25.

22. Kim N, Park RY, Cho SI, et al. Helicobacter pylori infection and development of gastric cancer in Korea: long-term follow-up. J Clin Gastroenterol 2008;42: 448-54.

23. Kahi CJ, Imperiale TF, Juliar BE, et al. Effect of screening colonoscopy on colorectal cancer incidence and mortality. Clin Gastroenterol Hepatol 2009;7: 770-75.

24. Burnett-Hartman AN, Newcomb PA, Potter JD. Infectious agents and colorectal cancer: a review of Helicobacter pylori, Streptococcus bovis, JC virus, and human papillomavirus. Cancer Epidemiol Biomarkers Prev 2008; 17: 2970-79.

25. Dejea C, Wick E, Sears CL. Bacterial oncogenesis in the colon. Future Microbiol 2013; 8: 445-60.

26. Kneller RW, You WC, Chang YS, et al. Cigarette smoking and other risk factors for progression of precancerous stomach lesions. J Natl Cancer Inst 1992; 84: 1261-6.

27. Han YM, Park JM, Kangwan N, et al. Role of proton pump inhibitors in preventing hypergastrinemiaassociated carcinogenesis and in antagonizing the trophic effect of gastrin. J Physiol Pharmacol 2015; 66:15967

28. Correa P, Piazuelo MB, Wilson KT. Pathology of gastric intestinal metaplasia: clinical implications. Am J Gastroenterol 2010;105: 493-8.

29. Selgrad M, Bornschein J, Kandulski A, et al. Helicobacter pylori but not gastrin is associated with the development of colonic neoplasms. Int J Cancer 2014; 135: 1127-31

30. Zhang Y, Hoffmeister M, Weck MN, et al. Helicobacter pylori infection and colorectal cancer risk: evidence from a large population-based case-control study in Germany. Am J Epidemiol 2012; 175: 441-50

31. Shmuely H, Melzer E, Braverman M, et al. Helicobacter pylori infection is associated with advanced colorectal neoplasia. Scand J Gastroenterol 2014; 49: 35-42

32. Strofilas A, Lagoudianakis EE, Seretis C, et al. Association of helicobacter pylori infection and colon cancer. J Clin Med Res 2012;4: 172-76

33. Guo Y, Li HY. Association between Helicobacter pylori infection and colorectal neoplasm risk: a metaanalysis based on East Asian population. J Cancer Res Ther 2014; 10 Suppl: 263-66

34. Venerito M, Vasapolli R, Rokkas T, et al. Helicobacter pylori and Gastrointestinal Malignancies. Helicobacter 2015; 20: 36-39

35. Zumkeller N, Brenner H, Zwahlen M, et al. Helicobacter pylori infection and colorectal cancer risk: a meta-analysis. Helicobacter 2006; 11: 75-80.

36. Joo YE, Park HK, Myung DS, et al. Prevalence and Risk Factors of Atrophic Gastritis and Intestinal Metaplasia: A Nationwide Multicenter Prospective Study in Korea Gut and Liver. 2013;7:303-10

37. Hirota WK, Zuckerman MJ, Adler DG et al. ASGE guideline: The role of endoscopy in the surveillance of premalignant conditions of the upper GI tract. Gastrointestinal Endoscopy.2006; 63:570-80.

38. P. Correa, "Human gastric carcinogenesis: amultistep andmultifactorial process-First American Cancer Society Award lecture on cancer epidemiology and prevention," Cancer Research, 1992;52: 6735-40. 
39. Yan Y, Chen YN, Zhao Q, et al. Helicobacter pylori infection with intestinal metaplasia: An independent risk factor for colorectal adenomas World J Gastroenterol. 2017;23: 1443-49.

40. Cummings LC, Cooper GS. Colorectal cancer screening: update for 2011. Semin Oncol 2011; 38: 483-89.

\section{TABLES}

Table 1. Distribution of demographical characteristics of the patients according to the presence of Helicobacter pylori infection and their association with colon neoplasia.

\begin{tabular}{|c|c|c|c|}
\hline Parameter & Hp positive & Hp negative & $\mathrm{P}$ value \\
\hline & (n: 99 ) & ( n: 115 ) & \\
\hline $\begin{array}{l}\text { Age, mean } \pm \text { SD } \\
\text { [years] }\end{array}$ & $47.60 \pm 15.44$ & $50.34 \pm 16.05$ & 0.206 \\
\hline $\begin{array}{l}\text { Gender, } n(\%) \text { Male } \\
\text { Female }\end{array}$ & $60(60.6) 39(39.4)$ & $65(56.5) 50(43.5)$ & 0.546 \\
\hline $\begin{array}{l}\text { Colon pathology, n (\%) } \\
\text { Normal colon Colon } \\
\text { neoplasm }\end{array}$ & $66(66.7) 33(33.3)$ & $84(73) 31(27)$ & 0.310 \\
\hline
\end{tabular}

Hp; Helicobakter pylori

Table 2. Distribution of demographical characteristics of the patients according to the presence of intestinal metaplasia and their association with colon neoplasia.

\begin{tabular}{|c|c|c|c|}
\hline Parameter & $\operatorname{IM}(+)$ & $\mathrm{IM}$ & $\mathrm{P}$ Value \\
\hline & (n: 68) & $(\mathrm{n}: 146)$ & \\
\hline $\begin{array}{l}\text { Age, mean } \pm \mathrm{SD} \\
\text { [years] }\end{array}$ & $57.88 \pm 13.98$ & $44.97 \pm 14.93$ & 0.000 \\
\hline $\begin{array}{l}\text { Gender, } n(\%) \text { Male } \\
\text { Female }\end{array}$ & $43(63.2) 25(36.8)$ & $82(56.2) 64(43.8$ & 0.328 \\
\hline $\begin{array}{l}\text { Colon pathology, n (\%) } \\
\text { Normal colon Colon } \\
\text { neoplasm }\end{array}$ & $41(60.3) 27(39.7)$ & $109(74.7) 37(25.3)$ & 0.033 \\
\hline
\end{tabular}

IM; intestinal metaplasia

Table 3. The association of intestinal metaplasia and Helicobacter pylori subgroups with colon neoplasia.

\begin{tabular}{llllll}
\hline & & & Normal colon $n$ & Colon neoplasm & \\
Group & IM & Hp & $(\%) 150(70.1)$ & $n(\%) 64(29.9)$ & value \\
\hline Group A & + & + & $14(56)$ & $11(44)$ & 0.098 \\
Group B & + & - & $27(62.8)$ & $16(37.2)$ & \\
Group C & - & + & $52(70.3)$ & $22(29.7)$ & \\
Group D & - & - & $57(79.2)$ & $15(20.8)$ & \\
\hline
\end{tabular}

Hp; Helicobakter pylori, IM; intestinal metaplasia 